\title{
ANP and AHP Method Approaches in Selecting of Tourism Attraction in Samarinda
}

\author{
Noor Alam Hadiwijaya ${ }^{1, *}$ Arbain Parid ${ }^{2}$ \\ ${ }^{1}$ Department of Information Technology, Politeknik Negeri Samarinda, 75131, Indonesia \\ ${ }^{2}$ Department of Electrical Engineering, Politeknik Negeri Samarinda, 75131, Indonesia \\ ${ }^{*}$ Corresponding author.Email: alamhadiwijaya@gmail.com
}

\begin{abstract}
The tourism sector, especially in Samarinda and its surroundings, is a sector that is experiencing quite dynamic development in supporting economic growth in the area. Apart from being one of the centers of education, Samarinda is also part of a tourist destination city in East Kalimantan. The objectives to be achieved in this study are to analyze and design, as well as to find out as well as compare the outputs or rankings of the two methods that will be used in supporting decisions for the selection of tourist objects in the city of Samarinda. Determining the criteria in this study was carried out through literature studies, surveys and interviews with related stakeholders, especially in the tourism sector. Furthermore, the criteria and sub-criteria are given a pairwise comparison assessment with a preference between 1-9 for the AHP method, then the ANP method will add an assessment of mutual influence between the criteria. The results to be obtained in this study can determine the best tourism object from several alternatives based on ranking as well as to determine the comparison of the output of the two methods whether the same or different.
\end{abstract}

Keywords: Tourism Site, ANP, AHP, Multi-Criteria Decision-Making.

\section{INTRODUCTION}

The tourism sector, especially in the city of Samarinda and its surroundings, is a sector that is experiencing quite dynamic development in supporting economic growth in the area. Apart from being one of the centers of education, Samarinda is also part of a tourist destination city in East Kalimantan. One thing that makes the city of Samarinda as a tourist destination is because in addition to the many and varied charms of tourist objects and tourist attractions, there are also facilities and infrastructure to support tourism such as accommodation, restaurants or restaurants, souvenir shops, and so on.

With the existence of several alternative tourist attractions that can be visited by tourists and in determining the subjectivity factor it is possible to occur, and with the hope that for an objective decision, it is necessary to decide the selection of tourist attractions to be visited using the approach. Analytic Network Process (ANP) and Analytic Hierarchy Process (AHP). ANP used because in this method there are factors that influence each other between criteria and it is a development of the AHP method, while in the AHP method there are no criteria that influence each other, so that in this study at the same time also want to know the comparison of the outputs or the ranking of the two methods, is it the same or different.

Based on a brief description of the research background, the formulation of the problem that will be discussed in this study is "How to make a design for decision support for tourism object selection in the city of Samarinda with the ANP and AHP approaches".

\section{METHOD}

\subsection{Analytic Hierarchy Process}

The steps in the AHP method consist of Saaty [1]; (1) Defining the problem by setting goals. (2) Decomposition, which describes the problem with creating a hierarchical structure of decisions starting with a general objective, followed by the main criteria, subcriteria, and option alternatives that will be prioritized. (3) Carry out comparative judgment (comparative assessment) by forming a pairwise comparison matrix then adding up each column of vectors in the matrix. (4) Normalize the matrix by dividing each comparison value by the total value of each column. After the matrix in this step is formed, the results are averaged (averaged) by rows so that the eigenvector (local priority vector) value 
is obtained from each paired comparison. (5) Test whether the filled comparison assessment is consistent or not, namely by calculating the consistency index (CI) and consistency ratio (CR) on the matrix. (6) Repeating steps 3,4 , and 5 for all hierarchical levels. (7) Applying the principle of synthesis, the priorities namely starting from the second level by multiplying the criteria weight (local weight) by the weight of the respective sub-criteria (local weight). This gives a composite priority or global weight (global priority) of each sub-criteria element then multiplied by the alternative weight (local weight priority) according to the respective sub-criteria and so on down to the bottom level. Then summed as a whole according to the number of comparisons of each alternative to each sub-criterion, so that the total weight (final result) of the weighting process for each alternative is obtained, which means that the priority alternative is the best choice.

\subsection{Analytic Network Process}

ANP was developed by Thomas L. Saaty in 1996. This development is due to the increasing number of decision-making problems that cannot be formed hierarchically. Every matter must have various elemental factors that are taken into consideration. In the ANP method, problem modeling is a combination of several clusters consisting of several elements that form a network. The Analytical Network Process (ANP) method is a development of the AHP method. The ANP method can improve AHP weaknesses in the form of the capacity to accommodate linkages between elements and alternatives [1]. ANP is an analysis tool that can represent the measure of interest of various parties by considering the dependency relationship between clusters and elements (nodes). ANP provides a more precise approach because ANP can handle complex problems related to dependence and feedback add to the hierarchical model to the network model.

The steps in the decision making system using the ANP method consist of [1]; (1) Defining the problem by determining objectives, (2) Decomposition, which describes the problem or problem by creating a hierarchical structure of decisions starting with a general objective, followed by criteria and or sub-criteria, as well as choice alternatives that will be prioritizing, (3) Carry out comparative judgment (comparative judgment) by forming a pairwise comparison matrix then adding up each vector column in the matrix, (4) Normalizing the matrix by dividing each comparison value by the total value of each column. After the matrix in this step is form, the results are averaged based on rows so that the eigenvector value of each pairwise comparison is obtaining, (5) Testing whether the filled comparison assessment is consistent or not, namely by calculating the consistency index $(\mathrm{CI})$ and consistency ratio $(\mathrm{CR})$ on the matrix. If CR 0.1, there will be revising judgment or re- assessment until the comparative assessment is declared consistent, namely $\mathrm{CR}<0.1$. To get the consistency index value, using equation (1) [2]:

$\lambda_{\text {max }}=\sum_{j=1}^{n} a_{i j} \frac{w_{j}}{w_{i}}$

After the value is obtained, then looking for the consistency index value is used equation (2) [2]:

$C I=\frac{\lambda_{\max }-n}{n-1}$

Then by using the random index (RI) value, the value of the consistency ratio (CR) is obtained by using equation (3) [2]:

$C R=\frac{C I}{R I}$

Consistency Ratio (CR) is a parameter used to check whether pairwise comparisons have been carried out consistently or no [3]. If the $\mathrm{CR}$ value is $\leq 0.1$, then the comparison matrix filling done by the user is consistent, (6) Repeating steps 3, 4, and 5 for all levels of the hierarchy, (7) Applying the principle of synthesis the priorities, namely starting from the second level by multiplying the weight of the criteria (local weight) with their respective local weight, (8) Super matrix formation, super matric is a two-dimensional matrix of elements with vector elements and priority from paired comparisons emerging from the corresponding super matrix column [4]. The matrix generated from the components with their elements and the matrix must be stochastic (each column has one number) to get the limiting result. The standard form of the super matrix is showing in equations (4) and (5) [5]:

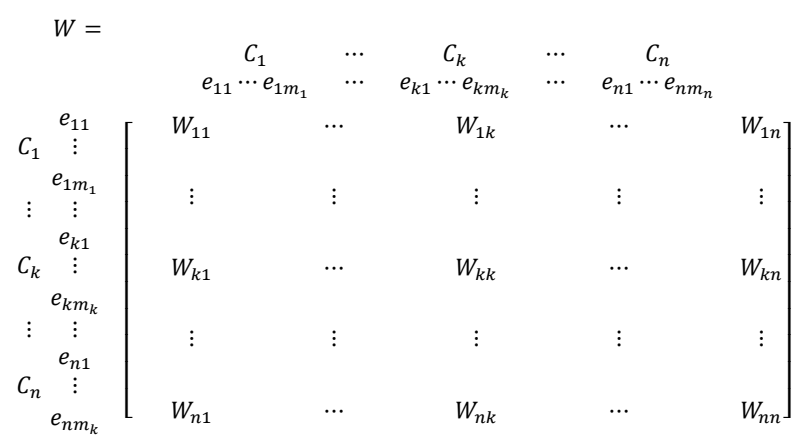

From the figure, the symbol $\mathrm{C}$ represents the clusters contained in a problem system. Meanwhile, e is an element contained in a cluster. Each column in Wij is an eigenvector that shows the importance of the ith element in a cluster to the jth element in the same or different clusters through pairwise comparisons. If the criteria are related to each other, entering the second row of the second column $(2,2) \mathrm{Wn}$ into W22 will show interdependence, and the supermatrix will be shaped like in equations (5) [6]: 


$$
W_{n}=\left(\begin{array}{ccc}
0 & 0 & 0 \\
W_{21} & W_{22} & 0 \\
0 & W_{32} & I
\end{array}\right)
$$

After the pairwise comparison process is carried out at each level, a local priority vector is obtained. Then the priority vector is derived into a supermatrix calculated in 3 steps, namely the Unweighted Supermatrix, created by collecting all the eigenvectors derived from each paired comparison between elements, whether affecting each other or not, Weighted Supermatrix, where the value is obtained by normalize the unweighted supermatrix, the Limit Supermatrix, to get the final value used in the selection, the calculation of the supermatrix limit, namely the stochastic weighted supermatrix, is then made by multiplying the weighted supermatrix continuously until a matrix has the same column value on each row . (9) Choosing the best alternative, the supermatrix formed in the third step covers the entire network. The alternative with the highest priority weight is the best choice. The form of the network in this study, the supermatrix includes the entire network as shown in Figure 1.

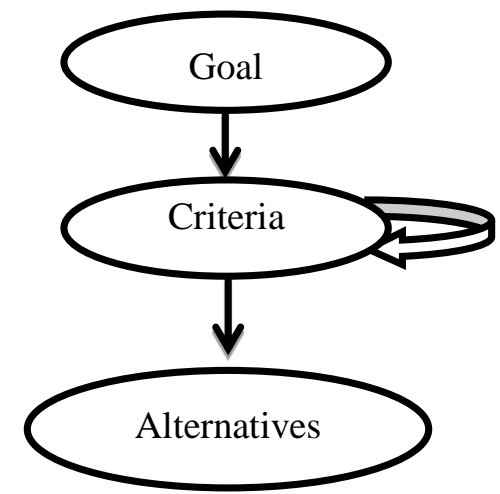

Figure 1 The network in this research

\subsection{Requirements Analysis}

Determining the priority of tourist destinations is modeled using the ANP approach as the basis for the decision-making process based on the ranking obtained from calculating the pairwise comparison matrix between existing criteria and sub-criteria using the Saaty 1-9 scale. So that in designing a model base subsystem it can be done in several steps [5]:

\subsubsection{Step 1: Establish Criteria for Determination of Tourist Attraction}

To determine the selection of the best tourist destinations and from the results of literature studies conducted, field observations, including interviews involving the opinions of experts in the field of tourism, the criteria that influence tourists (decision-makers) can be determined in determining tourist destinations. The criteria are grouped as follows:

1. Mileage; is the distance that must be traveled by tourists from the city center to tourist sites.

2. Facilities; are basic facilities that complement the location of a tourist attraction, namely a restaurant or restaurant, a place of worship, lodging or accommodation including toilets, parking lots, an information center, and a souvenir shop.

3. Cost; is a tourist fee in the form of an entrance ticket to enjoy a tour or tourist attraction issued by tourists.

\subsubsection{Step 2: Create a Hierarchical Structure of AHP and ANP Network}

The criteria that have been defined then organize the groups and group them according to their respective criteria into decision variables in order to form a hierarchical structure. Then determine the interdependence (interdependence) between criteria and sub criteria into the ANP model. Thus, the form of a hierarchical structure at the same time also shows the interdependence between the criteria illustrated in Figure 2 .

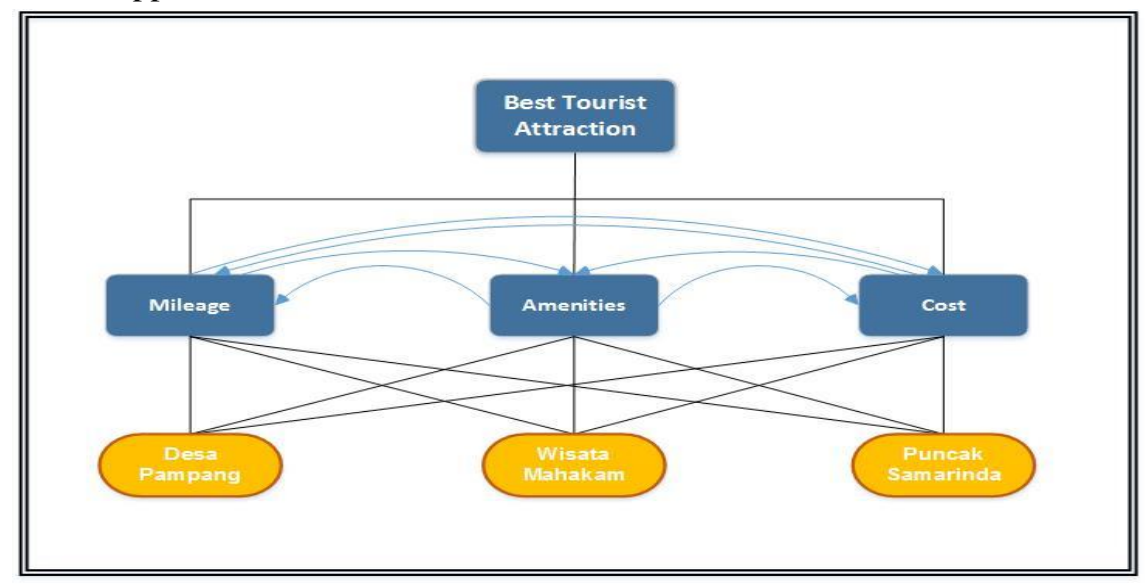

Figure 2 Hierarchical structure of AHP and ANP network 


\subsubsection{Step 3: Forming the pairwise comparison matrix and obtaining the eigenvector}

In this study, the comparison between criteria based on hierarchy and interdependent comparisons between criteria was carried out by experts in the form of a questionnaire. Pairwise comparison matrix between criteria based on ANP hierarchy and network structure. Table 1 shows the pairwise comparison matrix between criteria.

Table 1. Matrix of pairwise comparison between criteria

\begin{tabular}{lccrc}
$\begin{array}{l}\text { Tourism } \\
\text { Attraction }\end{array}$ & \multicolumn{4}{c}{ Tourism Attraction Criteria } \\
Criteria & Mileage & Amenities & Cost & Eigenvector \\
\hline Mileage & 1 & 3 & 4 & 0.623 \\
Amenities & 0.333 & 1 & 2 & 0.239 \\
Cost & 0.250 & 0.500 & 1 & 0.137 \\
\hline \multicolumn{4}{c}{$\lambda_{\max }=3,02 ; \mathrm{CI}=0,01 ; \mathrm{CR}=0,018 \leq 0,1$ Consisten }
\end{tabular}

After all the comparative assessments between alternative tourism objects with each of the existing criteria have been completed, the best alternative tourist destinations are obtained based on ranking. From the results of the calculation process carried out using a spreadsheet application, the final result is the best alternative destination, namely the first alternative is the wisata mahakam as the first rank with a weight of $57.8 \%$. The second alternative is the pampang as the second rank with a weight of $25.4 \%$, and the third alternative is the puncak samarinda as the third rank with a weight of $16.9 \%$. Thus, the first choice or the best choice is the wisata mahakam tourism attraction, followed by the Pampang and the puncak samarinda as the second and third choices. Table 2 shows the final results of the entire comparison calculation process in the form of the best alternative tourist destinations based on ranking using the AHP method.

Table 2. Combined eigenvector (Composite Weight) in AHP

\begin{tabular}{|c|c|c|c|c|c|c|c|c|c|}
\hline \multicolumn{4}{|c|}{ Composite Weight } & \multicolumn{2}{|c|}{ Desa Pampang } & \multicolumn{2}{|c|}{ Wisata Mahakam } & \multicolumn{2}{|c|}{ Puncak Samarinda } \\
\hline $\begin{array}{l}\text { Tourism } \\
\text { Criteria }\end{array}$ & Object & $\begin{array}{l}\text { Local } \\
\text { Weight } \\
\text { (LW) }\end{array}$ & $\begin{array}{l}\text { Global } \\
\text { Weight } \\
\text { (GW) }\end{array}$ & LW & GW & LW & GW & LW & GW \\
\hline Mileage & & 0.623 & & 0.221 & 0,138 & 0,685 & 0,427 & 0,093 & 0,058 \\
\hline Amenities & & 0.239 & & 0.334 & 0,080 & 0,568 & 0,136 & 0,098 & 0,024 \\
\hline Cost & & 0.137 & & 0.260 & 0,036 & 0,106 & 0,015 & 0,633 & 0,087 \\
\hline \multicolumn{3}{|c|}{ Total Weight } & & 0.816 & 0.254 & 1.359 & 0,578 & 0.825 & 0,169 \\
\hline \multicolumn{3}{|c|}{ Alternative Priority Options } & & \multicolumn{2}{|c|}{$2(25.4 \%)$} & \multicolumn{2}{|c|}{$2(57.8 \%)$} & \multicolumn{2}{|c|}{$3(16.9 \%)$} \\
\hline
\end{tabular}

Furthermore, in this study by using the same criteria and data and alternative tourism objects, then the calculation of data processing using the ANP method is added with an assessment of the comparison of the influence (inner dependence) between each criteria, so that later the output of the two the method.

\subsubsection{Step 4: Forming an interdependent pairwise comparison matrix}

Table 3 shows the inner dependence of the pairwise comparison matrix which shows the effect of one criterion compared to other criteria.

Table 3. Matrix of interdependent pairwise comparison between criteria

\begin{tabular}{lllc}
\hline Distance $\left(\mathrm{C}_{1}\right)$ & $\mathrm{C}_{2}$ & $\mathrm{C}_{3}$ & $\mathrm{e}$ Vector $\left(\mathrm{W}_{22}\right)$ \\
\hline Facility $\left(\mathrm{C}_{2}\right)$ & 1 & 3 & 0.250 \\
Cost $\left(\mathrm{C}_{3}\right)$ & 0.333 & 1 & 0.750 \\
$\lambda_{\max }=2,000 ; \mathrm{CI}=0,000 ; \mathrm{CR}=0,000 \leq 0,1$ & & & $\mathrm{e}$ Vector $\left(\mathrm{W}_{22}\right)$ \\
Facility $\left(\mathrm{C}_{2}\right)$ & $\mathrm{C}_{1}$ & $\mathrm{C}_{3}$ & 0.250 \\
Distance $\left(\mathrm{C}_{1}\right)$ & 1 & 0.500 & 0.750 \\
Cost $\left(\mathrm{C}_{3}\right)$ & 2 & 1 & $\mathrm{e}$ Vector $\left(\mathrm{W}_{22}\right)$ \\
$\lambda_{\max }=2,000 ; \mathrm{CI}=0,000 ; \mathrm{CR}=0,000 \leq 0,1$ & & & 0.250 \\
Cost $\left(\mathrm{C}_{3}\right)$ & $\mathrm{C}_{1}$ & $\mathrm{C}_{2}$ & \\
Distance $\left(\mathrm{C}_{1}\right)$ & 1 & 1 & 0.750 \\
Facility $\left(\mathrm{C}_{2}\right)$ & 1.000 & 1 & \\
$\lambda_{\max }=2,000 ; \mathrm{CI}=0,000 ; \mathrm{CR}=0,000 \leq 0,1$ & & & \\
\hline
\end{tabular}




\subsubsection{Step 5: Comparison of Alternative Tourism Attraction Based on Criteria}

To choose the best alternative tourism object, it is necessary to make a comparison between the alternative tourism objects against each of the existing criteria. In this study, the comparative assessment between alternative tourism objects with each criterion is carried out by tourists according to their needs as a decision maker whose appraisement refers to the Saaty fundamental scale.

\subsubsection{Step 6: Determine the ANP weight and choose the best tourist attraction}

After all the eigenvectors from each level of the hierarchy are obtained including the interdependent network between the criteria, all of the eigenvectors are synthesized and processed in succession into a supermatrix which is then called an unweighted supermatrix which holds all the eigenvector weights then processed in weighted supermatrix to form a stochastic matrix and form a limit matrix to get the best alternative for tourist destinations.

\section{RESULT AND DISCUSSION}

From Table 5 the unweight supermatrix whose values are a collection of comparison eigenvectors between criteria, interdependent between criteria, and alternative comparison eigenvectors against existing criteria. While for Table 6 is the weighted supermatrix which values are the result of normalization of the unweighted supermatrix table by dividing each element by the total value of each vector column to obtain a stochastic value. Furthermore, multiplication is carried out continuously on the weighted supermatrix table until a matrix is obtained that has the same column value in each row, namely by ranking the matrix with large numbers, so that the supermatrix limit table is obtained as shown in Table 7, it can be seen that the best alternative tourism object is successive. Order based on ranking are; Mahakam tourism object is in the first rank (1) with a priority value of 0.464 , the peak of Samarinda is in the second rank (2) with a priority value of 0.269 , and the village of Pampang is in the third rank (3) with a value of 0.267

Table 4. Unweighted Supermatriks

\begin{tabular}{lllcllcc}
\hline & Goal & $\mathbf{C}_{1}$ & $\mathbf{C}_{2}$ & \multicolumn{1}{c}{$\mathbf{C}_{\mathbf{3}}$} & DP & WM & PS \\
\hline Goal & 0 & 0 & 0 & 0 & 0 & 0 & 0 \\
Mileage $\left(\mathbf{C}_{1}\right)$ & 0.623 & 0.000 & 0.250 & 0.250 & 0 & 0 & 0 \\
Amenities $\left(\mathbf{C}_{2}\right)$ & 0.239 & 0.250 & 0.000 & 0.750 & 0 & 0 & 0 \\
Cost $\left(\mathbf{C}_{3}\right)$ & 0.137 & 0.750 & 0.750 & 0.000 & 0 & 0 & 0 \\
Desa Pampang & 0 & 0.221 & 0.334 & 0.261 & 1 & 0 & 0 \\
Wisata S. Mahakam & 0 & 0.685 & 0.568 & 0.106 & 0 & 1 & 0 \\
Puncak Samarinda & 0 & 0.093 & 0.098 & 0.633 & 0 & 0 & 1 \\
\hline
\end{tabular}

Table 5. Weighted Supermatriks

\begin{tabular}{llcccccc} 
& Goal & $\mathbf{C}_{\mathbf{1}}$ & $\mathbf{C}_{\mathbf{2}}$ & \multicolumn{1}{c}{$\mathbf{C}_{\mathbf{3}}$} & \multicolumn{1}{c}{ DP } & WM & PS \\
\hline Goal & 0 & 0 & 0 & 0 & 0 & 0 & 0 \\
Mileage $\left(\mathbf{C}_{\mathbf{1}}\right)$ & 0.623 & 0,000 & 0,125 & 0,125 & 0 & 0 & 0 \\
Amenities $\left(\mathbf{C}_{2}\right)$ & 0,239 & 0,125 & 0,000 & 0,375 & 0 & 0 & 0 \\
Cost $\left(\mathbf{C}_{3}\right)$ & 0,137 & 0,375 & 0,375 & 0,000 & 0 & 0 & 0 \\
Desa Pampang & 0 & 0.111 & 0.167 & 0.130 & & 0 & 0 \\
Wisata S. Mahakam & 0 & 0.343 & 0.284 & 0.053 & 0 & 1 & 0 \\
Puncak Samarinda & 0 & 0.047 & 0.049 & 0.317 & & 0 & 0 \\
\hline
\end{tabular}

Table 6. Limit Supermatriks

\begin{tabular}{lllll}
\hline & Goal & Mileage $\left(\mathbf{C}_{1}\right)$ & Amenitie $\left(\mathbf{C}_{2}\right)$ & Cost $\left(\mathbf{C}_{3}\right)$ \\
\hline Goal & 0 & 0 & 0 & 0 \\
Mileage $\left(\mathbf{C}_{1}\right)$ & 0 & 0 & 0 & 0 \\
Amenities $\left(\mathbf{C}_{2}\right)$ & 0 & 0 & 0 & 0 \\
Cost $\left(\mathbf{C}_{3}\right)$ & 0 & 0 & 0 & 0 \\
Desa Pampang & 0,267 & 0,251 & 0,301 & 0,275 \\
Wisata Mahakam & 0,464 & 0,507 & 0,455 & 0,287 \\
Puncak Samarinda & 0,269 & 0,241 & 0,244 & 0,438 \\
\hline
\end{tabular}




\section{CONCLUSION}

First, Decision support for tourism object selection in Samarinda city has been successfully designed in the form of process modeling, database management subsystem, model base management subsystem, and user interface subsystem. Secondly, based on the output resulting from the application of the two methods, the ranking is almost the same (there is no significant difference). Lastly, With the same parameters of the output generated from the ANP method, namely between rank 1, 2 and 3 does not show a value (weight) that is not much different, while in the AHP method with the same parameters between rank 1, 2 and 3 have a big difference in weight, this is because it is influencing by the comparison of the influence between criteria (inner dependence) on the ANP method. The suggestion for further research can be carried out using other methods in the same domain, or a combination using the assessment of fuzzy models or group decision support system (GDSS).

\section{ACKNOWLEDGMENT}

The source of funding in this research is funded by the Pusat Penelitian dan Pengadian Kepada Masyarakat (P3M) at the Politeknik Negeri Samarinda. The author also thanks the reviewer and also all parties who have helped start from the preparation stage, data collection and analysis until the final completion of the research report and research outputs so that everything goes well.

\section{REFERENCES}

[1] T. L. Saaty, Decision Making with Dependence and Feedback-The Analytic Network Proces. Pittsburgh: RWS Publications, 1996.

[2] T. L. Saaty, The Analytic Hierarchy Process. McGraw-Hill, 1980.

[3] Marimin, Teknik dan Aplikasi Pengambilan Keputusan Kriteria Majemuk. Jakarta: Grasindo.

[4] T. L. Saaty, Theory and Applications of the Analytic Network Process: Decision Making with Benefits, Opportunities, Costs, and Risks. Pittsburgh: RWS Publications, 2005.

[5] P. F. and M. K. H. Hsu, "Applying The ANP Model for Selecting The Optimal Full-Service Advertising Agency," Int. J. Oper. Res., vol. 8, pp. 48-58, 2011.

[6] Y. Chen, C. Lin, and J. Lu, "The analytic network process for the banking sector: An approach to evaluate the creditability of emerging industries," African J. Bus. Manag., vol. 5, no. 4, pp. 1343 1352, 2011, doi: 10.5897/AJBM10.1090. 